\title{
Discourse Analysis of Teacher and Students in Pre- Intermediate English Class
}

\author{
Mohammad Shah Zaki \\ PhD Cand. Istanbul Aydin University \\ Department of Language and Literature
}

\begin{abstract}
This research will examine the classroom discourse and interactions between a teacher and students in an ESL class. It will analyze how discourse occurs and how it can facilitate language learning. The participants were adult university students or employees. Via live classroom observation and audio recording of classes, the data were collected. The findings suggest that the teacher controlled all students, and led all class activities and the teaching process. The teacher frequently used pronouns 'you', 'we', 'I' while teaching as well as words such as "perfect," "correct," and "very good" to motivate students in-class participation. Students mostly used the pronoun 'I' to answer the questions. Most of the questions were closed-ended, so students did not have a chance to elaborate or share their ideas. The discourse occurred in an "IRF" -- Initial, Response, and Follow up. Lack of coherence and cohesion were widely visible in classroom interaction and most of the sentences uttered were ungrammatical. ${ }^{1}$
\end{abstract}

Keywords: coherence, cohesion, discourse, data, IRF

\section{Introduction}

Education is a very broad field, and discourse analysis is a method to analyze communication in the classroom or in written exchanges to understand the intended meaning and the outcomes. Thus, discourse analysis is a linguistic approach and has been applied widely in social sciences over the past few decades. Discourse analysis helps language teachers to provide variety and meaning to the lesson. It is beneficial for teachers to categorize their weaknesses and strengths, and ultimately, students benefit from a greater understanding of the lessons. It is also valuable for teachers to understand the classroom communication and discover whether the lesson has been implemented in the best possible way. According to Brown \& Yule (1983), a different approach to the study of language itself is presented through discourse study. Discourse analyzes what language is used for, but it does not analyze language structures. Therefore, what the language is used for is the focus of discourse analysis, not the language structures.

${ }_{1}^{1}$ Research Article 


\section{Literature review}

\subsection{Definition of Discourse Analysis}

There are different definitions of discourse analysis, depending on the theoretical framework. The followings are some definitions:

Fairclough (1995, as cited in Alsoraihi, 2019) stated that discourse analysis is the analysis of different texts within the scope of sociocultural practice. It requires paying attention in all levels such as phonological, grammatical, lexical, or vocabulary; at a higher level, it requires consideration of exchange systems, structures of argumentations, and generic structures. Furthermore, concerning communication, Bavelas, Kenwood, \& Philips (2002, as cited in Alsoraihi, 2019) refer to it as "the systematic study of naturally occurring communication in the broadest sense, at the level of meaning rather than as psychical acts or features" (p. 81).

Wennerstrom (2003, as cited in Alsoraihi, 2019) has defined discourse analysis as "the study of naturally occurring language in the context in which it is used" (p. 81). Contrary to this definition, Rymes (2008, as cited in Alsoraihi, 2019) has defined it as "the study of how language-in-use is affected by the context of its use" (p. 81). Moreover, Gee (2011, as cited in Alsoraihi, 2019) gives a similar definition and calls it "the study of language-in-use. To say in a better way, it is the study of language at use in the world, not just to say things, but to do things" (p. 81). Expanding further, Hai (2004, as cited in Alsoraihi, 2019) has defined discourse analysis as "the analysis of language beyond the sentence. This contrasts with types of analysis which are mainly concerned with grammar, word meanings, sounds, and rules for making meanings" (p. 81).

\subsection{Significance of Discourse Analysis to Language Teaching}

Language teaching aims to help language learners to communicate, regardless of their language level. The use of the target language gives learners real opportunities to experience and practice communication. Discourse analysis has emerged as an essential component in teaching language through the communicative approach (Olshtain \& Celce-Murcia, 2001, as cited in Alsoraihi, 2019). According to Berrocal et al., (2016, as cited in Alsoraihi, 2019) to analyze the way foreign and native speakers use language within the social context, discourse analysis focuses on language forms and functions in social interactions to improve language acquisition. Moreover, it concentrates on details of speech to convey the social meaning used by the people using the components of language represented in morphology, syntax, phonetics, and phonology.

Most of the researchers believe that in language teaching and learning, discourse analysis and pragmatics are two essential parts. Discourse analysis deals with intended meaning and its relationships within the context, while pragmatics deals with the interpreted meaning from linguistic processing and social interaction. Furthermore, according to Hai $(2004$, as cited in Alsoraihi, 2019) how to interpret the relationship between the different units of the language in an attempt to reach a comprehensive framework of meaning is the concern of discourse analysts.

Discourse analysis has a significant role in language teaching and learning. Classroom discourse analysis enhances teachers' and students' meta-discursive reflection, and at the level of current globalized educational systems, it is considered critical in multilingual education. Classroom discourse analysis helps us to understand the complex relationship 
between students' and teachers' interaction, and its effects on the learning process taken place in the classroom environment (Woodward-Kron \& Remedios, 2010, as cited in Alsoraihi, 2019). According to (Martinez, 2012; Qomi, 2019, \& Rymes, 2008, as cited in Alsoraihi, 2019) classroom discourse analysis helps us understand to what extent teachers use the language in the classroom; it also provides us with valuable information about language analysis and its reflection on cultural awareness. Moreover, it enables both teachers and students to understand the different contexts and enable them to identify language corresponding functionality.

It should be acknowledged that discourse analysis is a powerful tool to create new forms of identities and strengthen students in a globalizing world. Discourse analysis is used by the teachers to develop social interactions in classroom environments. Tang $(2008$, as cited in Alsoraihi, 2019) stated that the study of discourse analysis and the employment of it in different contexts can result in:

- Language awareness enhancement

- Critical mindset

- Greater understanding of everyday contexts

- Better understanding of things taught about language in the classroom

- Developing the mechanism used in teaching English language

- Improvement of communication sensitivity (p. 84).

- Moreover, research conducted by Alzobidy \& Khan (2019) revealed

The important factors to be considered are: comprehension and interpretation, individual variations that influence classroom discourse processing, for example, syntactic patterns, working memory, meaning, and interpretation of classroom discourse (p. 274).

In a study conducted by Luo (2013) the class assumed teacher-reading and student-repeating sessions, presenting a lack of opportunity in the classroom for the students to develop learner autonomy in English learning. Likewise, other classroom research showed limited opportunities for student-initiated participation in the classroom discourse or situations that require students' higher-order thinking cf. Jan \& Hardman (2007, as cited in Luo, 2013). Most students did not have the opportunity to use the target language independently and only replied to the teacher in the chorus or repeated what the teacher uttered. That means almost all the classroom activities were teacher-fronted drills (Luo, 2013).

According to Widdowson (1979, as cited in Sinurat, n.d., \& Mit'ib, 2010) "knowing a language does not mean understanding, speaking, reading and writing a sentence, it means knowing how sentences are used to communicate effectively" (p. 11). To do so it is necessary to increase the level of student participation in the classroom, to facilitate student-centered language teaching, and reduce the teacher's dominance in the classroom. Simultaneously, teachers should praise and encourage whenever students do positive work. Teachers and students influenced by language discourse research can avoid pragmatic difficulties in language teaching. Both form and function should be studied together, and avoid focusing too much on structuralism while not reducing the importance of functional studies (Sinurat, n.d.). Furthermore, the teachers should provide students with a suitable environment for interactions and real opportunities to exercise the language in a different situation to enhance the language acquisition and language development processes with a communicative perspective (Alsoraihi, 2019). 
Foreign language learners learn and build their second language system naturally and unconsciously based on their first language because learners' first language competence is the tool they bring for understanding. Thus, second language competence develops on the common ground of the first language; the new rules assimilated in L2 build on existing L1 competence. Moreover, both first and second language systems do not form distinct language systems in the mind; they form connections in vocabulary, syntax, phonology, and pragmatics (Domalewska, 2015).

This study aims to analyze the discourse between teachers and students in a Pre-Intermediate English class. The research mostly focuses on whether the teacher discourse facilitates language learning or impedes it. Moreover, it also seeks to understand how the language teaching and learning process happens.

\section{Methodology}

The researcher of this study observed and recorded a pre-intermediate English-as-a-secondlanguage class to observe discourse in a real classroom setting. Before implementing this study, the researcher received permission from the teacher to observe and record the teaching process for forty-five minutes. The researcher took notes and transcribed the recorded audio onto a script to analyze the discourse.

\subsection{Participants}

The participants of this study were male and female Turkish students at pre-intermediate English level. The participants were not school students, however; most were university students. Participants of this study had different purposes to learn English. Some of them study English to find a better job, others to facilitate other university subjects.

\subsection{Data collection}

The researcher selected the Pre-Intermediate English class to collect the research data because all the students were Turks, but the teacher was not. Therefore, English language interaction represented the type of class where the students and teacher come from different language backgrounds. To collect the data, the researcher observed the teaching process and took notes from students and teacher's interaction. In addition to that, the researcher recorded the language learning process and then transcribed it into the script.

\subsection{Data analysis}

The researcher implemented both qualitative and quantitative methods to analyze the collected data. After taking note of the observation process and transcribing the recorded interactions between teacher and students into the script, the researcher evaluated and analyzed the discourse. To analyze the discourse, the researcher did not use any specific software. The analysis involved reading the text carefully and highlighted the content and function words which were frequently exchanged between teacher and students during the language teaching process. Highlighted words were then listed on a separate sheet of paper to see how often these words were used by both teacher and students. Each set of words was written in a separate column and counted at the end. In addition, the script was analyzed using Microsoft Excel and Microsoft Word to calculate the percentage of frequently used discourse words in the class. Consequently, the qualitative and quantitative analyzed data were combined and summarized together to come up with an appropriate conclusion. 


\subsection{Instrument}

In this study, the instruments which were used to collect the necessary data concerning classroom discourse and interactions between teacher and students were tape recording and observation. The personal observations were necessary for the researcher to know how the teacher carries on the lesson and how the students react to the teacher's questions and comments. These observations were recorded in hand-written notes. In addition, the script from the audio recording was used for further analysis. Also, Microsoft Excel and Word were used as instruments to accurately analyze the collected data.

\section{Results}

This study focused on analyzing the teaching process and the interaction between teachers and students. The findings reveal that the teacher used 'lock-step' teaching, which means the teacher controlled all students, doing the same activity at the same rhythm and space while making presentations and checking exercise answers. Also, he followed the same coursebook/curriculum as the students, worked through the activities, and led all the classwork. He frequently questioned students about the topic and led them to answer. Most of the questions were closed-ended; although a small number were open-ended. In close-ended questions, students had no chance to express their ideas and opinions, so, the language learning process was impeded. On the other hand, open-ended questions let students share their ideas and experiences while answering the questions. This not only builds selfconfidence for the students but also facilitates the language learning process.

Using discourse analysis, the interactions between teachers and students did not follow up with coherence and cohesion. Most of the students' answers had grammatical problems which caused a lack of cohesion and coherence. Two examples are 'seven-thirty o'clock' and 'just to know.' To overcome the problem, students talked in their mother tongue to help each other in responding to the questions. As Sopio (2018) has stated, "(E)ven though in most cases L1 was not encouraged to be used during the English lessons, students unconsciously or consciously still found ways of incorporating their mother language in the process of the L2 acquisition" (p. 178).

Through classroom observation and transcription analysis, it could be seen that the lesson was teacher-centered and conducted in lockstep. The figure below demonstrates the teacher talk, especially the usage of pronouns while teaching the lesson.

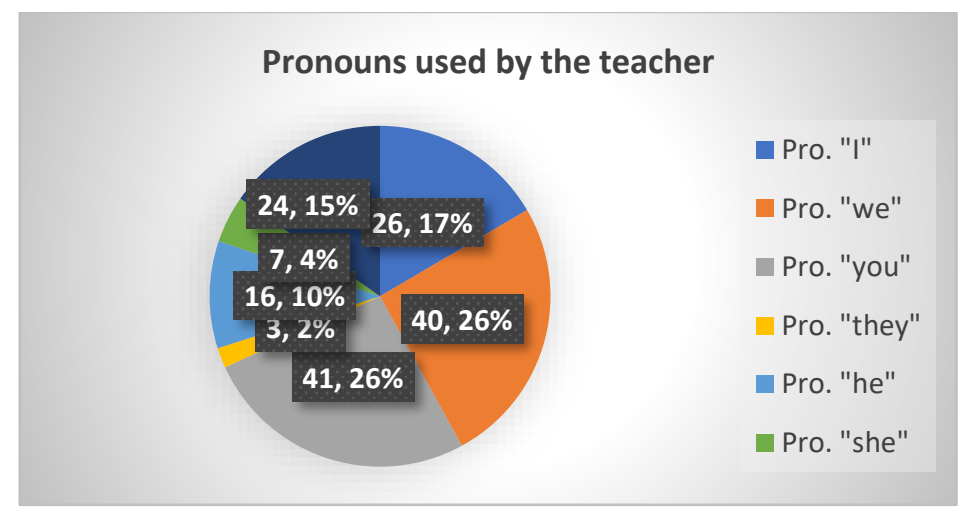

Figure 1. Pronouns used by the teacher. 
During the lesson, the teacher used the pronoun ' $y o u$ ' 41 times and ' $w e$ ' 40 times which covered $26 \%$ of the talk respectively. The pronoun 'you' asks direct questions or opinions of the students about the subject, whereas the pronoun ' $w e$ ' shows shared responsibilities and the

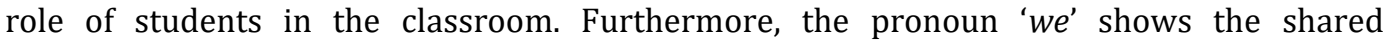
responsibility of both teachers and students while learning a language. According to Karapetjana (2011, as cited in Hakansson 2012) usage of the pronoun 'we' can be divided into two categories, the inclusive ' $w e$ ' used to refer to the speaker and the listener/viewer, and the inclusive ' $w e$ ' that refers to both the speaker and the listener or listeners. Furthermore, the teacher used the pronoun ' $I$ ' 26 times while teaching the lesson, amounting to $17 \%$ of the talk. By using the pronoun ' $I$,' the teacher conveyed his opinions and made his speech more subjective as well as declaring his authority to the class. The remaining subjective pronouns were used during the interaction between teachers and students to determine student's participation in the class.

\section{MOTIVATING WORDS USED BY THE TEACHER}
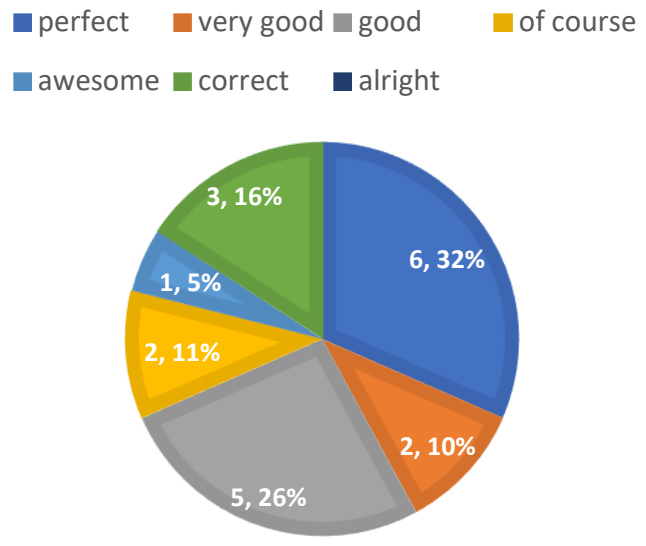

Figure 2. Motivating words used by the teacher.

In addition to the pronouns, the findings of this study revealed that the teacher praised, encouraged, and motivated students by using motivating words such as: 'perfect, very good, good, of course, awesome, correct, and alright'. Usage of such words not only motivates, builds self-confidence, and encourages students to participate in the lesson but also ease the learning process and strengthen the relationship between teacher and students, which is one the most influential aspects of learning. It is very important to make the classroom atmosphere relaxed and friendly. Ramage (1990, as cited in Zaman, 2015) stated that "teachers should try to make the learners engage in their learning that can influence learners' motivation to attain their desired goal" (p.9). All the researchers agreed that teachers are one of the important factors that can influence learners' motivation. Motivating words of the teachers create an enjoyable and friendly environment, build mutual respect, and encourage students to frankly share their ideas and experiences with the class. Teachers should relate lessons to the surrounding environment and real-life situation, so this is not possible unless they motivate students to feel free while interacting in the class. 


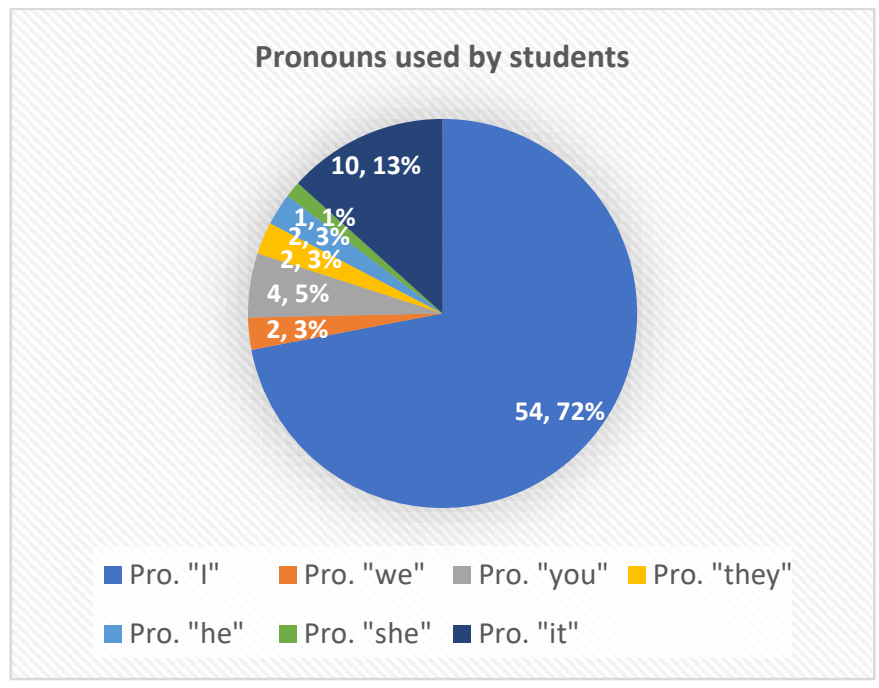

Figure 3. Pronouns used by students

Furthermore, the findings showed the frequent use of pronouns ' $I$ ' and ' $i t$ ' by the students during teacher and students' interactions. The pronoun ' $I$ ' shows that the speaker expresses his/her ideas or opinions about the topic or question. Also, the pronoun ' $I$ ' positively describes oneself and highlights his/her personal qualities. By using the pronoun ' $I$,' students wanted to convey or reflect their point of view and made the answer or speech more subjective rather than objective. This pronoun was used 54 times, which covered $72 \%$ of the interaction with the teacher. The pronoun ' $i t$ ' was the second most frequently used pronoun, and referred to a place, thing, or non-human being. It was used 10 times, covering 13\% of the talk. The other personal pronouns were rarely used during teacher-students' interaction in the class.

In short, the observation and audio recording showed that the class was teacher-centered and the teacher used the lockstep teaching method. The teacher presented all of the lessons and talked more than seventy percent of the time, the students only listened and answered the questions whenever they were asked.

\section{Discussion}

Classroom observations and audio recordings of the teaching process in a Pre-Intermediate English class enabled analysis of a teacher's discourse, which is a very important factor in language learning. Discourse theory suggests that a teacher should be more aware while interacting or presenting the lesson because the language, choice of words, tone of voice, even way of dressing, and social behavior have an influential impact on learning. This study highlighted some of the most important points.

The teacher mostly used the pronouns 'you', ' $w e^{\prime}$ and ' $I$ ' as well as others while he was conducting language teaching. The usage of the pronoun 'you' indicates that the speaker refers to either a specific person in the class or generally to all students in the class. In some cases, the teacher needs to use the pronoun 'you' not only in praising students, but also highlighting shortages or problems that everyone should consider. The pronoun ' $w e$ ' declares that both the teacher and students are part of the lesson and make them responsible for the learning 
process. Also, it raises the importance of the students as a target source and, if there are no students, there is no class. Also, usage of the pronoun ' $I$ ' shows the speaker's ideas, opinions and makes everything more personal and subjective. However, sometimes teachers use themselves as an example to encourage or motivate students to take part in the class, which is a good strategy.

Furthermore, the teacher motivated the students whenever they answered the question even if their response was not appropriate. The teacher should praise students and encourage them to participate in the class. On one hand, this action reduces their anxiety, fear of being criticized; on the other hand, it builds self-esteem and gives importance to them as a part of the language learning process. In this way, the teacher created a friendly, less fearful, and less tense classroom for the students, and that is one of the most important factors for language learning.

The interaction between teacher and students often had the students using the pronoun ' $I$ ' in their responses. It means that most of the questions completely referred to their personal views or ideas about the specific topic or ideas. There were fewer open-ended questions compared to close-ended questions. Close-ended questions do not help the students' learning process and hold them to a specific point even when they cheat from others. By contrast, openended questions help them express their ideas and accelerate the learning process and create a fruitful classroom atmosphere.

The other very visible point in the class was a lack of coherence and cohesion while teachers and students were interacting. Most of the students' sentences were ungrammatical and structurally direct translations of Turkish into English. Sometimes, students talked in their native language to help each other in responding to the questions. Sopio (2018) stated that "despite the fact that in most cases first language was not encouraged to be used during the English lessons, students unconsciously or consciously still found ways of incorporating their mother language in the process of the second language acquisition" (p.178).

\section{Conclusion}

In short, the discourse analysis in Pre-Intermediate English language class revealed that the teacher mostly used ' $y o u$ ', ' $w e$ ', and ' $I$ ' pronouns in language teaching to either explain the lesson or question students. Moreover, to praise and encourage students to participate in classroom discussions, teachers motivate them by using words like 'perfect,' 'very good,' 'correct,' and so on. This creates a friendly environment for the students and facilitates the learning process. However, he used the lockstep teaching method and tried to control and direct all the classroom discourse and activities. The teacher initiated the questions, students answered, and then the teacher followed up. Since students' sentences were ungrammatical and sometimes helped each other in their mother tongue, their discourse lacked coherence and cohesion. On the other hand, the teacher tried to create a friendly and enjoyable classroom environment by praising students.

Furthermore, the students frequently used the pronoun ' $I$ ' to answer the teacher's questions. Usage of the pronoun ' $I$ ' demonstrated that students were expressing their personal views, ideas, and thought in their answers. Students did not share their knowledge or elaborate in answers because the questions were close-ended. Such kinds of questions limit students' choices, impede their creativity, and most importantly encourage them to copy answers. 


\section{References}

[1] Alsoraihi, M. H. (2019). Bridging the gap between discourse analysis and language

[2] classroom practice. English Language Teaching, 12 (8), 81-86. doi: 10.5539.

[3] Brown, G. \& Yule, G. (1983). Discourse analysis. Cambridge, U. K.: Cambridge

[4] University Press.

[5] Domalewska, D. (2015). Classroom discourse analysis in EFL elementary lessons.

[6] International Journal of Language, Literature and Linguistics, 1 (1), 6-8. doi: 10.7763/IJLLL.

[7] Khan, A., \& Alzobidy, S. A. M. (2019). Classroom discourse of English language teachers

[8] at Secondary School Level. International Journal of English Linguistics, 9 (1), 270272. doi: 10.5539/ijel. v9n1np269.

[9] Luo, W. H. (2013). A study of discourse in relation to language learning in English classes co-taught by native English-speaking teachers and local teachers in Taiwan. English Language Teaching, 6 (7), 104-105. doi: 10.5539/elt. v6n7p96.

[10] Mit'ib, M. A, (2010). Discourse analysis and English language teaching: A functional perspective. Qadissiya Journal of Literature and Educational Sciences, 9 (3-4), 40-43.

[11] Sinurat, Y. D. (n.d.). Discourse analysis studies: The contributions in language teaching. English department, faculty of teacher training and education Lancang Kuning University, 11-13.

[12] Sopio, T. (2018). The role of mother tongue in second language acquisition. International Journal of Multilingual Education, 11, 176-178. ISSN 1987-9601.

[13] Zaman, J. (2015). Role of motivation in second language learning: A study of Private University Students in Bangladesh. BRAC, Institute of Languages. 